\title{
Wireless Sensor Network Coverage Measurement and Planning in Mixed Crop Farming
}

\author{
Ndzi D. L ${ }^{1}$, Harun A. ${ }^{2}$, Kamarudin L.M. ${ }^{3}$, Ramli M.F. ${ }^{2}$, Zakaria A. $^{2}$, Shakaff A.Y.M. ${ }^{2}$, Jaafar M.N. $^{4}$, Zhou, ${ }^{1}{ }^{1}$ \\ \& Farook, R. S. ${ }^{2}$ \\ ${ }^{1}$ School of Engineering, University of Portsmouth, Portsmouth, UK \\ ${ }^{2}$ School of Mechatronic Engineering, University Malaysia Perlis (UNIMAP), Perlis, Malaysia \\ ${ }^{3}$ School of Computer and Communication Engineering, University Malaysia Perlis (UNIMAP), Perlis, Malaysia \\ ${ }^{4}$ School of Bioprocess Engineering, University Malaysia Perlis (UNIMAP), Perlis, Malaysia \\ E-mail: david.ndzi@port.ac.uk
}

\begin{abstract}
Wireless sensor network technology holds great promise for application in a wide range of areas, both to monitor and control a variety of systems. Whilst the use of sensors has found natural applications within the manufacturing sector, application in agriculture is still in its infancy and has been used largely to only monitor the environment. The use of technology in the agricultural sector to improve crop yield, quality and to foster sustainable agriculture can be regarded as one of the areas that will provide food security to the expanding global population and to mitigate food shortage precipitated by unpredictable weather patterns. This paper presents a Wireless Sensor Network coverage measurements in a mixed crop farming, modeling and deployment architecture taking into account the different signal propagation scenarios and attenuation factor of different crops. Most importantly, the paper presents wireless sensor network deployment architecture for a mixed crop trial field over an area of $54,432 \mathrm{~m}^{2}$, which is $4 \%$ of the total area to be covered by the final network.
\end{abstract}

\section{Keywords:}

\section{INTRODUCTION}

Advancements in electronics and communication have made possible the development of small sensors that can be integrated with miniature communication modules to make up wireless nodes which inputs for different types of sensors. A number of standards exist for short range communications which include WIFI, Bluetooth, ultra-wideband and ZigBee. Amongst these technologies, ZigBee is more suitable for wireless sensor network because of its low energy requirements. Studies in Error! Reference source not found.show that the IEEE802.15.4 (ZigBee) modulation scheme enables a range extension of up to 8 times for the same amount of energy compared to IEEE802.15.1 (Bluetooth). Although a general purpose technology, one of the areas where wireless sensor network (WSN) technology is expected to make a global impact is in agriculture [1]. Food security, urbanization, population growth and climate change have attracted attention not just to food production, but also to food management, transportation, traceability and the need to reduce food wastage. These can be accomplished with the use of wireless systems, provided appropriate sensors and controls are implemented.

In crop farming, WSN can be used to monitor and control factors that influence crop growing conditions and yields, determine the optimum time to harvest, determine which cultivar is more suitable for each condition, detect disease, control machinery, etc [1][5][6][13]. In animal farming, wireless sensors can be used to monitor animal movement, activities, health condition, numbers, disease, interaction and diversity [2][7][8][9][14][15]. However, the biggest impact of WSN in agriculture is expected to be the implementation of semi-autonomous and autonomous controls in farming that would optimize resources, mitigate the impact of climate change, and reduce cost, labour, and increase productivity.

A good number of studies have been carried out on WSN architecture in agriculture [6]. Limited studies have been reported on the models that could be used to deploy these networks [3][10][26]. One of the reasons for the lack of appropriate models is because most crops and environments vary. In addition, the ad-hoc mode of operation of most of these nodes mean that researchers have paid very little attention to individual nodes but to the whole network. For precision farming in mixed crop agriculture, the performance and reliability of each node is important. This is because different plants have different requirements, root zones/depth, and tolerant periods to adverse conditions before lasting damage occurs or yields are affected. To implement an autonomous system with context-aware sensor fusion and control, network reliability is required. Therefore this paper reports on measurements in a 12 acre farm used as a test-bed for WSN deployment.

Vegetation attenuation models [30] reported in open literature make a number of assumptions that include the assumptions that the communication system set-up uses the classical master-slave configuration and that one of the 
transmitters is at a higher height or most often, situated outside the vegetation. In WSN where nodes operate in a peer-to-peer configuration and sometimes in an ad-hoc manner, very little studies have been carried out to develop appropriate models for network planning. Therefore, this paper evaluates a generic form of one of the vegetation attenuation models [28], validates path loss models and proposes appropriate parameters that could be used in the implementation of the models.

This paper is organized as follows; Section 2 described the WSN devices that were used, the measurement set-up and the layout of the agro-farm. Details of the various types of plant are also provided. Section 3 describes the measurement results and provides details of the various models that have been evaluated, including those that have been developed for network coverage. Section 4 described the network planning and possible performance indicator for the farm. In addition, it discusses how the sensors are most likely going to be used. It also gives the cost factor for the network. The conclusions are provided in Section 5 where the possible impact of the technology on biodiversity and sustainable agriculture is provided.

\section{WIRELESS NETWORK COVERAGE IN AGRICULTURE}

Several researchers have focused on proposing solutions for node deployment in WSN. For fixed or semi-mobile network, pre-determined topologies have been widely used. In mobile environments, stochastic approach is widely employed. Whichever approach is used, there are two important desirable network characteristics; achieving kconnectivity and coverage.

\section{SYSTEM DESCRIPTION AND MEASUREMENTS}

\subsection{Measurement System}

This study was conducted using wireless sensor devices (motes) from MEMSIC which are equipped with Atmel RF230 radio chip that implements the IEEE802.15.4 standard. In the $2.4-2.5 \mathrm{GHz}$ band there are 16 channels with each channel having a bandwidth of $3 \mathrm{MHz}$ separated by $5 \mathrm{MHz}$. It is designed to support an effective data rate of $256 \mathrm{kbps}$. The devices were configured to transmit a total power of $3.2 \mathrm{dBm}$. The receiver sensitivity is rated as -91 $\mathrm{dBm}$. Omni-directional antennas with gains of $4.3 \mathrm{dBi}$ were used to ensure greater coverage and each mote was powered by 2 AA size batteries [7]. Although other systems could have been used, the authors elected to use samples of commercially available WSN devices to ensure that a derived deployment plan is not only feasible but also implementable within a short timescale.

Link estimation is an essential part of network planning, prediction and network protocols development and evaluation. A number of quality measures were specified and are implemented in most of the devices that support the IEEE802.15.4 standard. These include Relative Signal Strength Indicator (RSSI) and Link Quality Indicator (LQI). RSSI gives an estimate of the signal power received and LQI is based on chip error. Studies based on devices that implemented the IEEE802.15.4 reported that RSSI was only reliable for detecting good links and is unreliable at signal values that are close to the limits of the receiver sensitivity [18]. However, Srinivasan and Levis, using 30 wireless sensor nodes, have shown that RSSI, for a given link, has very small variation over time and the packet reception rate is at least $85 \%$ for signals above the sensitivity threshold of $-85 \mathrm{dBm}$. At smaller signal strengths, there is no correlation between packet reception rate and RSSI which may be more strongly influenced by system noise. Comparison of LQI and RSSI showed that LQI only offers a better correlation with packet reception rate when averaged over a large number of packets. The study also showed that over a small number of packets, LQI varied over a wide range making it an unreliable parameter for short term measurements.

For communication between two nodes there are three states in wireless links: connected, transitional and disconnected states [20]. In the transitional state, communication links are unreliable and are characterized by large variations in the link quality parameters, such as RSSI.

Based on the studies into the reliability of RSSI and the need for measurements at many positions, measurements reported in this paper use RSSI as a measure of the link quality. The RSSI value of the Atmel RF230 radio device in the IRIS motes is saved as a 5-bit value indicating the receive power over a dynamic range of $81 \mathrm{dBm}$ from $-91 \mathrm{dBm}$ to $-10 \mathrm{dBm}$. RSSI computation in the device does not distinguish between IEEE 802.15.4 signal and other signal source [21]. Therefore it is critical to conduct the studies where there were no IEEE802.11 devices Error! Reference source not found.. Using the Basic Operating Mode, the relationship between RSSI values, which is updated every 2 us, and the received signal is given by 


$$
P_{R F}=R S S I_{\text {Base }}+R S S I
$$

where $\operatorname{RSSI}_{\mathrm{BASE}}$ is equal to $-91 \mathrm{dBm}$.

\subsection{Measurement Environment and Set-up}

These studies were aimed at establishing network coverage in areas cover by the following crops: corn, herbs (Misai Kuching), cashew nut, mango and guava trees. In addition, studies were conducted in open fields in areas with soil and grass covering to establish connection between sensor network cluster head. Images of some of the areas where measurements were conducted are shown in Fig. 1. Also shown is the partitioning of the crops growing area. The whole 12 acres is not illustrated as part is covered by greenhouse and other buildings.

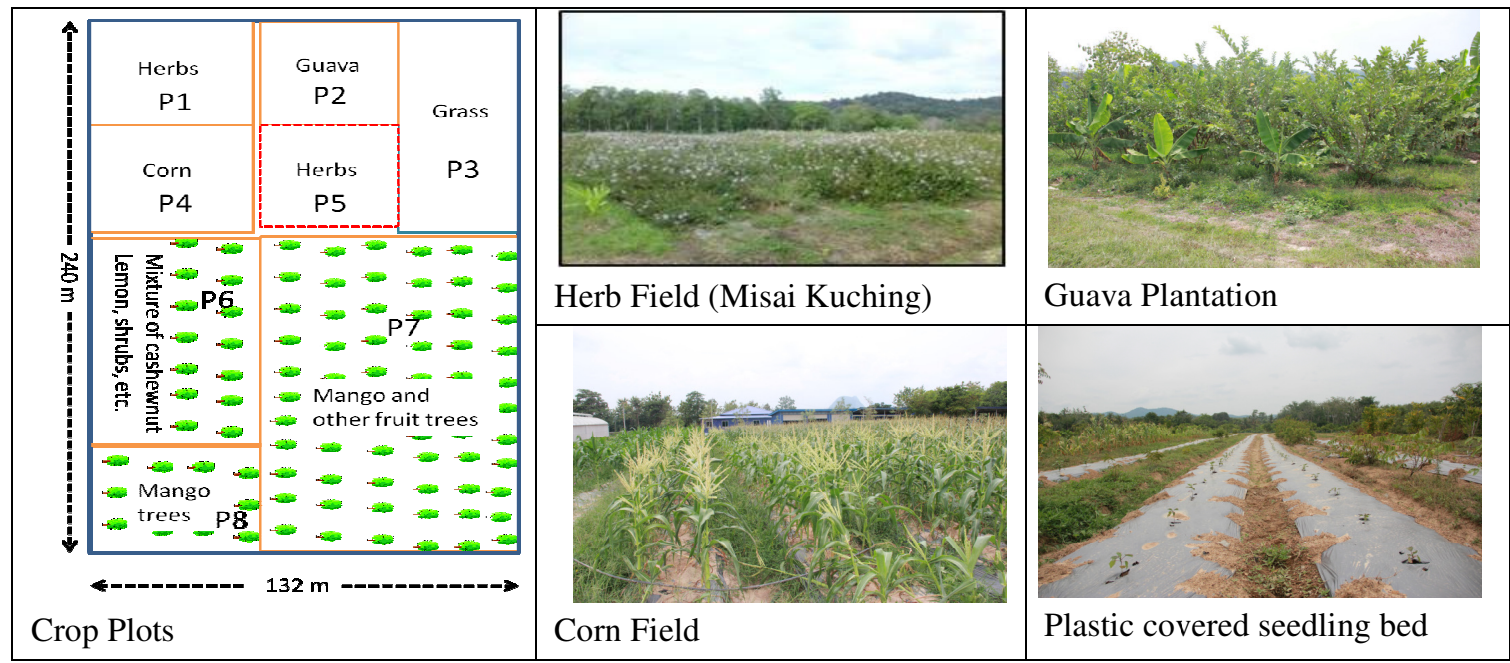

Fig. 1 Measurement environments

These areas were selected to provide the generic network coverage models and represent samples of the crops in the farm. Although the WSN deployment will focus on this part in the initial phase, network coverage is planned for the complete 250 acre site. The site includes rubber plantation and natural tropical forest. The study reported in this paper were conducted with the sensors positioned closed to the ground, $15 \mathrm{~cm}$ above ground, and at $1 \mathrm{~m}$ heights. Whilst WSN coverage can benefit from the nodes being positioned at heights that are above the surrounding vegetation, this will either be cost inefficient or require constant repositioning due to the time variant nature of plant height.

Different types of plants require different sets of growing conditions. This study is a small part of a bigger research programme to better understand plant growth, impact of climate change, productivity and biodiversity. The conditions that will be monitored and controlled would require some of the sensors to be placed in the soil whilst others would be placed at the base on the ground, trunk and branch heights of the plants. The distances between the sensor(s) and the wireless module, and the wireless module and the antenna need to be small to reduce signal losses in the units.

All trees or crops were planted in rows with regular spacing between plants and rows. The number of crop rows per bed depends on the type of crop. The planting configurations are illustrated in Fig. 2. The specifications for each type of crop, including the dimensions, are given in Table 1. Two rows of the guava trees are inter-spaced with banana plants. However the link set-up was such that the banana plants had very little or no influence on the results obtained.

Table 1 Crop specification and planting geometry

\begin{tabular}{|l|l|l|l|l|l|}
\hline Crop & $\begin{array}{l}\text { Row spacing } \\
\text { X }(\mathrm{cm})\end{array}$ & $\begin{array}{l}\text { Plant spacing } \\
\text { Y }(\mathrm{cm})\end{array}$ & $\begin{array}{l}\text { Average plant } \\
\text { height }(\mathrm{cm})\end{array}$ & $\begin{array}{l}\text { Average stem } \\
\text { diameter }(\mathrm{cm})\end{array}$ & $\begin{array}{l}\text { Planting } \\
\text { rows per bed }\end{array}$ \\
\hline Corn & 40 & 30 & 210 & 3.5 & 2 \\
\hline Cashew nut & 200 & 200 & 150 & 6 & 1 \\
\hline Herb -Misai Kuching & 30 & 30 & 50 & 0.6 & 2 \\
\hline
\end{tabular}




\begin{tabular}{|l|l|l|l|l|l|}
\hline Guava & 180 & 180 & 240 & 6 & 1 \\
\hline
\end{tabular}

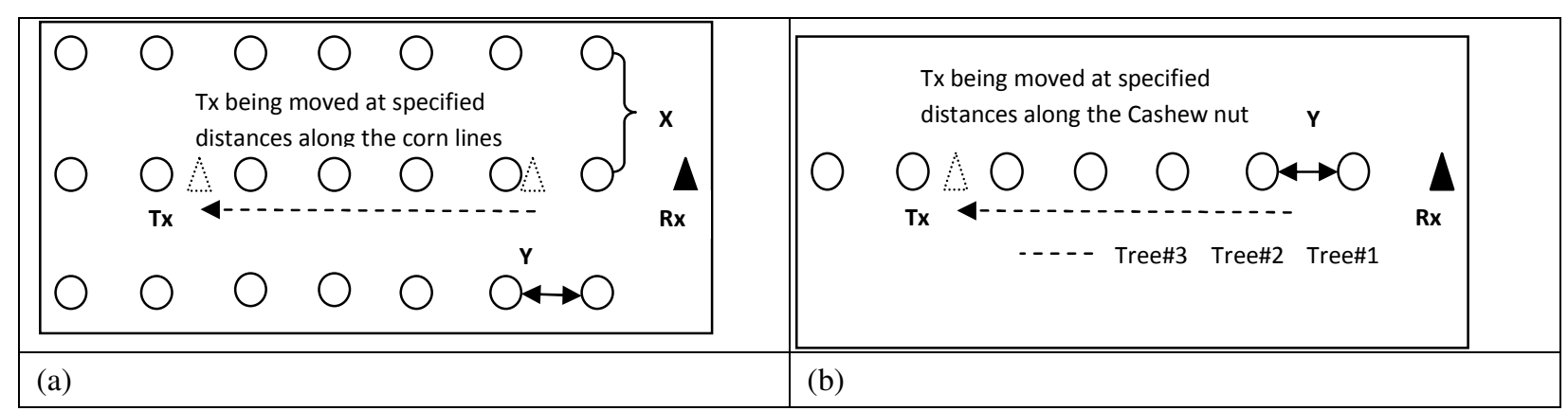

Fig. 2 Crops planting pattern; (a) two or more rows of plants per bed and, (b) one row of plants per bed.

\section{MEASUREMENT RESULTS}

This study was conducted at $15 \mathrm{~cm}$ and $1 \mathrm{~m}$ antenna heights to assess system coverage at these antenna heights. Since one of the important cost factors in WSN deployment is power consumption, the WSN nodes can be configured to transmit different power levels. Doubling the transmitted power level only extends the range by a factor of $\sqrt[n]{2}$, where $\mathrm{n}$ is the power decay exponent which may not be commensurate to the increase in energy depletion rate. In free space, the range will be increased by a factor of 0.414 . Therefore the rate of radio wave attenuation is not only critical for network coverage but also for network planning and power optimisation.

Fig. 3 shows the signal variation with range over grass and soil covered surfaces at the two antenna heights. One interesting observation is that on grass, the range is at least $10 \mathrm{~m}$ longer at $15 \mathrm{~cm}$ antenna height than on the soil. At $77 \mathrm{~m}$, for $1 \mathrm{~m}$ antenna height, the signal over the grass field is also $8 \mathrm{~dB}$ stronger compared to the same distance over the soil. This can be attributed to surface roughness with the grass having a smoother surface than soil.

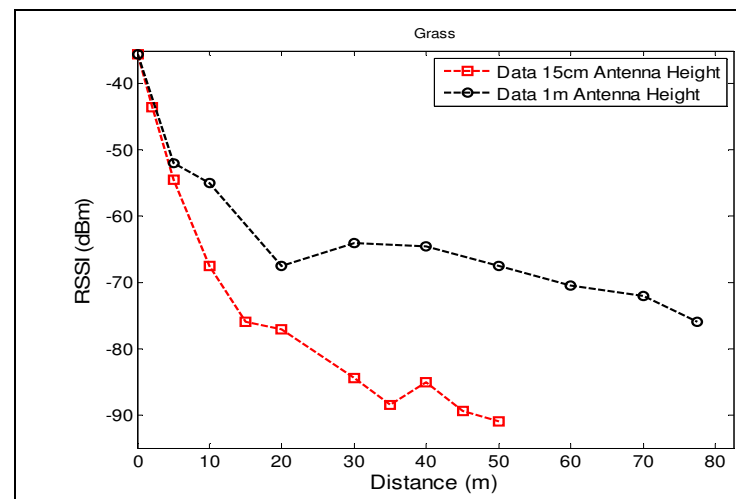

(a)

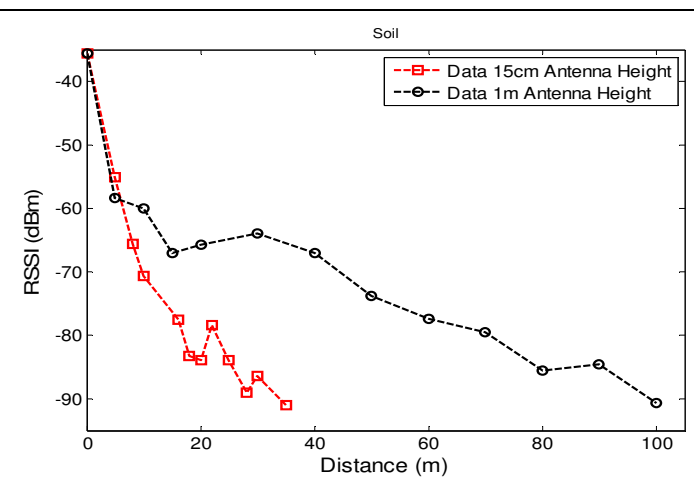

(b)

Fig. 3 Signal variation with range, (a) over grassfield and, (b) over soil covered grounds

Fig. 4 shows the trend of signal power with distance in herbs and in the corn field. At $15 \mathrm{~cm}$ height, the range of the wireless sensor nodes with $-91 \mathrm{dBm}$ noise floor is limited to a maximum of $25 \mathrm{~m}$. At $1 \mathrm{~m}$ height, the antenna is higher than the herbs and the range increases significantly with a $22 \mathrm{~dB}$ margin above the receiver noise floor at 28 $\mathrm{m}$. Measurements were not conducted beyond $28 \mathrm{~m}$ because of the limited range of the plot. Compared to measurements over the grass field and soil covered ground, at $28 \mathrm{~m}$ the signal strength in the herbs at $1 \mathrm{~m}$ antenna height is $4 \mathrm{~dB}$ weaker. At $1 \mathrm{~m}$ height, the antenna was still below the height of the corn. Fig. 4(b) shows that there is very little difference in signal strength between the two antenna heights. It is interesting to note that at ranges less than $8 \mathrm{~m}$, attenuation is higher at $1 \mathrm{~m}$ antenna height compared to $15 \mathrm{~cm}$. This can be explained by the fact that the foliage is thicker at $1 \mathrm{~m}$ height thereby attenuating the coherent components much more that at $15 \mathrm{~cm}$ height which is dominated by corn stocks with fewer leaves. At higher vegetation (corn) depth, there are more diffused signal components at higher heights than at the base and this may account for the lower attenuation observed at $1 \mathrm{~m}$ antenna height in Fig. 4(b). 


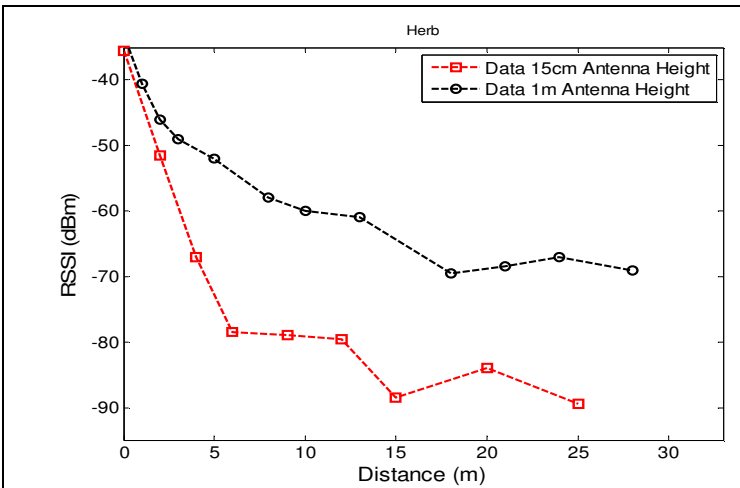

(a)

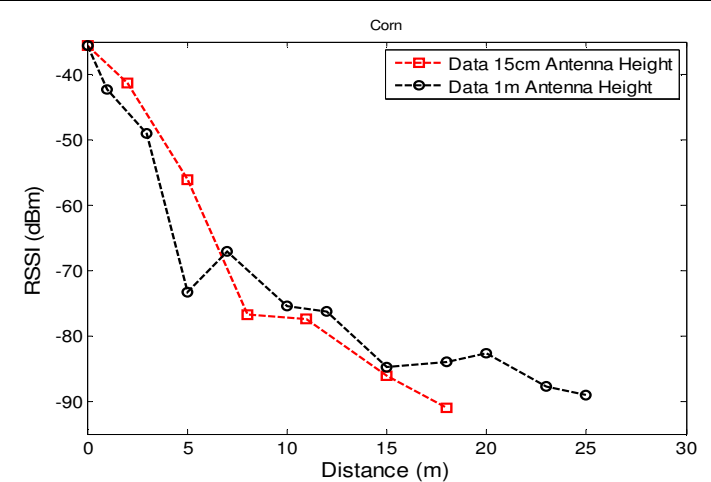

(b)

Fig. 4 Signal varation with range in (a) Herb and, (b) corn

Fig. 5 shows the results obtained from measurements conducted on cashew nut trees and guava. It should be noted that none of the antenna heights were above the tree canopy. The figure shows that there is very little or no difference in signal attenuation at the two antenna heights, except that there is significantly more signal variation at $15 \mathrm{~cm}$ antenna height.

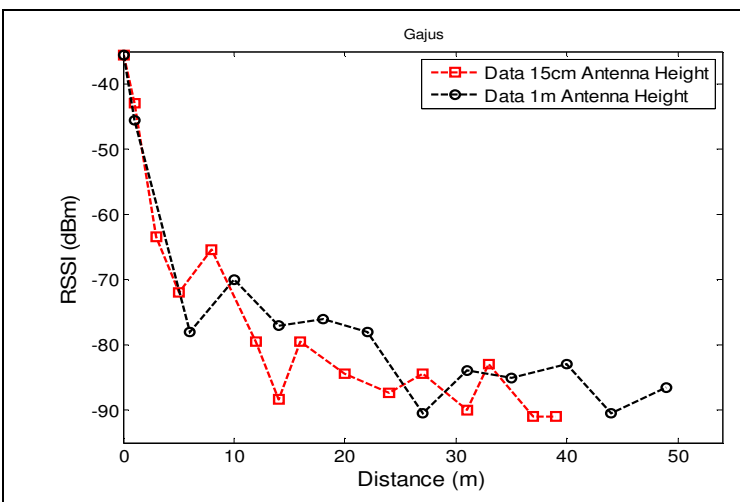

(a)

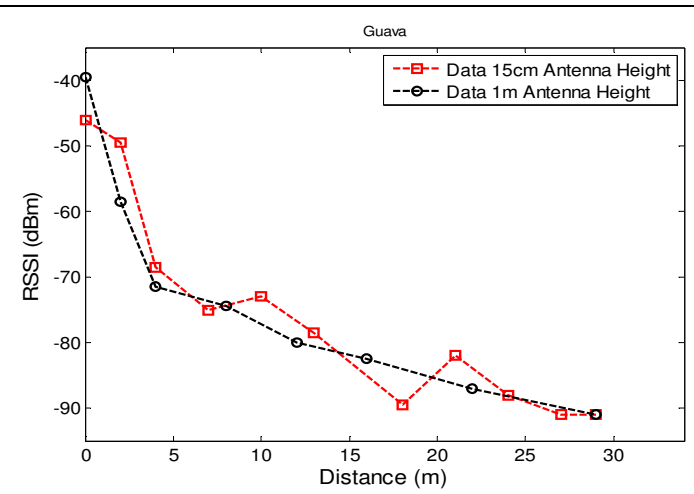

(b)

Fig. 5 Signal variation with range in (a) cashew nut and (b) guava plantation

\section{MODELLING OF WIRELESS SIGNAL COVERAGE}

Results in Section 4 show that wireless sensor node range can only be extended if the antenna is position above the vegetation canopy. Signal propagation involves the interaction between the direct, scattered and reflected components. Severely scattered signal would results in dropped packets, significant increase in the number of retransmissions and an increase in energy consumption and hence, shorter battery life.

The models that are widely used in wireless sensor networks in the presence of vegetation include the two-ray ground reflection model and the Weissberger [28] vegetation attenuation models. All the vegetation attenuation models that have been developed aim at wide area communication networks where, at least, one antenna is located at a significant height. In addition, communication devices transmit higher power levels than wireless sensor nodes with ranges of more than $300 \mathrm{~m}$. Examples of vegetation attenuation models include those recommended by the International Telecommunication Union (ITU) [22]. A good survey of vegetation attenuation models is given in [24][25].

In a transmission medium, the received power, $\mathrm{P}_{\mathrm{r}}$, at the transmitter is given by (2)

$$
P_{r}=P_{t} G_{t} G_{r}\left(\frac{\lambda}{4 \pi d}\right)^{n}
$$

where $P_{t}$ is the transmitted power, $G_{t}$ and $G_{r}$ are the transmitter and receiver antenna gains, respectively; $\lambda$ is the wavelength of the radio waves and $d$ is the distance between the transmitter and receiver antennas; and $n$ is the rate at which power decays with distance. In free space, $n$ is equal to 2 . This equation assumes a homogeneous medium where the rate of signal attenuation is constant. However, in the presence of vegetation, the transmission medium is 
not homogeneous neither in density, orientation nor dimension of the vegetation components. For normalized signal, equation (2) can be simplified to equation (3). This can be converted into a linear equation using logarithm as in equation (4)

$$
\begin{aligned}
& \mathrm{P}_{\mathrm{r}}=\mathrm{P}_{0} \mathrm{~d}^{-\mathrm{n}} \\
& \mathrm{P}_{\mathrm{r}}(\mathrm{dB})=\mathrm{P}_{0}(\mathrm{~dB})-10 * \mathrm{n} * \log _{10} \mathrm{~d}
\end{aligned}
$$

In equation (4), $\mathrm{d}$ is the normalized distance. Compared to published vegetation attenuation models such as the Modified Exponential Decay (MED) model and the Non-zero Gradient model, this is a simplified model [25][26]. From a propagation mechanisms perspective, at very shallow vegetation depths, signal propagation is dominated by coherent components which decrease rapidly with distance. Beyond this point propagation is mainly due to forward scatter dominated by diffuse components. However, because of the small transmitted power from wireless sensor nodes, most scattered or diffused components are too weak to be detectable. Nonetheless, their presence is illustrated by the reduction in signal decay gradient at distances further from the transmitter.

The generalized form of the MED vegetation attenuation model is given by

$$
\mathrm{P}_{\mathrm{r}}(\mathrm{dB})=X f^{Y} d^{Z}
$$

where $\mathrm{f}$ is the frequency in megahertz $(\mathrm{MHz}), \mathrm{d}$ is the vegetation depth in meters and, $\mathrm{X}, \mathrm{Y}$ and $\mathrm{Z}$ are the model parameters. Different values have been proposed in literature for this model under a variety of names e.g. COST 235, ITUR, FITUR and Weissberger [22][25][28]. To assess the application of this model in wireless sensor networks, the generalized form of the MED model has been fitted to the measured data in the presence of vegetation.

Linear regression technique has been used to estimate the value of $n$ in equation (4). In the presence of vegetation, the MED model has also been fitted to the data, including the Free Space Loss (FSL) model. Fig. 6 shows examples of fittings to the measured data, the $\mathrm{n}$ estimates and the root mean square errors (given in brackets) between the models and the measured data. The figures show that the linear model, equation (4), generates the smallest root mean square error. The advantage of the linear and FSL models is that they apply to cases with or without vegetation in the propagation paths.

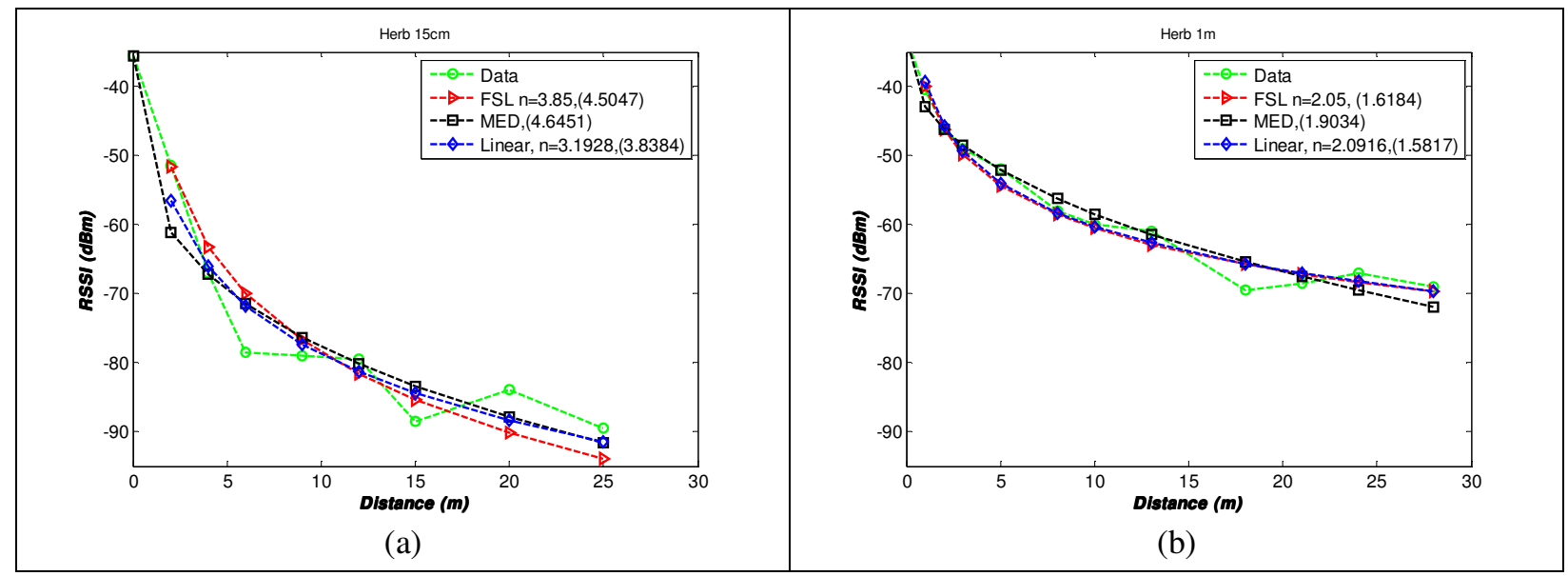

Fig. 6 Modelling of signal power variation with distance in herb plantation at (a) $15 \mathrm{~cm}$ and, (b) $1 \mathrm{~m}$ antenna heights.

The values of the parameters of the models together with the root mean square errors (RMSE) between the models and the measured data are given in Table 2.The results show that the linear model offers the highest accuracy. The simplicity of the model and the limited range of wireless sensor nodes mean that there is limited reason to use complex vegetation attenuation models developed for wide area communication networks. Some of the fitted parameter values give very optimistic network coverage predictions at $1 \mathrm{~m}$ antenna height and pessimistic estimates at $0.15 \mathrm{~m}$ antenna height. For example, the network coverage at $1 \mathrm{~m}$ antenna height is estimated to be approximately $180 \mathrm{~m}$ on the soil covered surface. For reliable communication, maximum range of the node should be assumed to be limited to $80 \mathrm{~m}$. 
Table 2 Parameters of fitted models and the root mean square errors between the model and the data

\begin{tabular}{|c|c|c|c|c|c|c|c|c|c|c|}
\hline & \multirow{2}{*}{$\begin{array}{c}\text { Antenna } \\
\text { Height }(\mathrm{m})\end{array}$} & \multicolumn{3}{|c|}{ Linear Model } & \multicolumn{2}{|c|}{ FSL Model } & \multicolumn{4}{|c|}{ MED Model } \\
\hline & & $\mathrm{n}$ & Po & RMSE & $\mathrm{n}$ & RMSE & $x$ & $y$ & z & RMSE \\
\hline \multirow{2}{*}{ Soil } & 1 & 2.34 & -36.86 & 4.33 & 2.14 & 4.40 & -- & -- & -- & -- \\
\hline & 0.15 & 4.04 & -28.75 & 2.32 & 3.16 & 3.24 & -- & -- & -- & -- \\
\hline \multirow{2}{*}{ Cashew Nut } & 1 & 2.34 & -49.53 & 4.41 & 3.01 & 5.49 & 19.91 & 0.00 & 0.26 & 5.05 \\
\hline & 0.15 & 2.77 & -47.50 & 4.23 & 3.34 & 5.04 & 18.51 & 0.00 & 0.31 & 5.16 \\
\hline \multirow{2}{*}{ Corn } & 1 & 3.45 & -40.48 & 3.95 & 3.49 & 3.95 & 27.81 & -0.10 & 0.46 & 4.75 \\
\hline & 0.15 & 5.30 & -23.88 & 3.00 & 3.70 & 6.24 & 11.01 & -0.05 & 0.71 & 4.29 \\
\hline \multirow{2}{*}{ Herb } & 1 & 2.09 & -39.41 & 1.58 & 2.03 & 1.61 & -- & -- & -- & -- \\
\hline & 0.15 & 3.19 & -46.90 & 3.84 & 3.83 & 4.50 & 14.01 & 0.05 & 0.31 & 4.65 \\
\hline \multirow{2}{*}{ Grass Field } & 1 & 1.79 & -39.02 & 2.52 & 1.72 & 2.53 & -- & -- & -- & -- \\
\hline & 0.15 & 3.46 & -32.59 & 1.72 & 2.93 & 3.01 & 25.31 & -0.10 & 0.41 & 3.49 \\
\hline \multirow{2}{*}{$\begin{array}{c}\text { Plastic covered } \\
\text { bed }\end{array}$} & 1 & 1.73 & -43.43 & 1.91 & 1.99 & 2.25 & -- & -- & -- & -- \\
\hline & 0.15 & 2.82 & -38.94 & 2.49 & 2.74 & 2.50 & -- & -- & -- & -- \\
\hline \multirow{2}{*}{ Guava } & 1 & 2.58 & -52.41 & 1.63 & 3.67 & 4.77 & 5.71 & 0.15 & 0.31 & 1.93 \\
\hline & 0.15 & 3.23 & -44.03 & 3.43 & 3.56 & 3.67 & 1.41 & 0.25 & 0.46 & 4.25 \\
\hline
\end{tabular}

To assess the impact of antenna height gain on wireless node coverage, additional studies were conducted in an open grass field to evaluate the effect of changes in antenna height on network coverage. Fig. 7 shows the signal variation with distance for antenna heights of $0.15,0.5$ and $1 \mathrm{~m}$ antenna heights. The results show that up to approximately 31 $\mathrm{m}$, the received signal power for $0.5 \mathrm{~m}$ antenna height is either equal to or greater than the received signal power at the antenna height of $1 \mathrm{~m}$. Ground reflected paths will exist when the boundary of the first Fresnel Zone, $h_{0}$, is equal to or greater than, the antenna height [23].

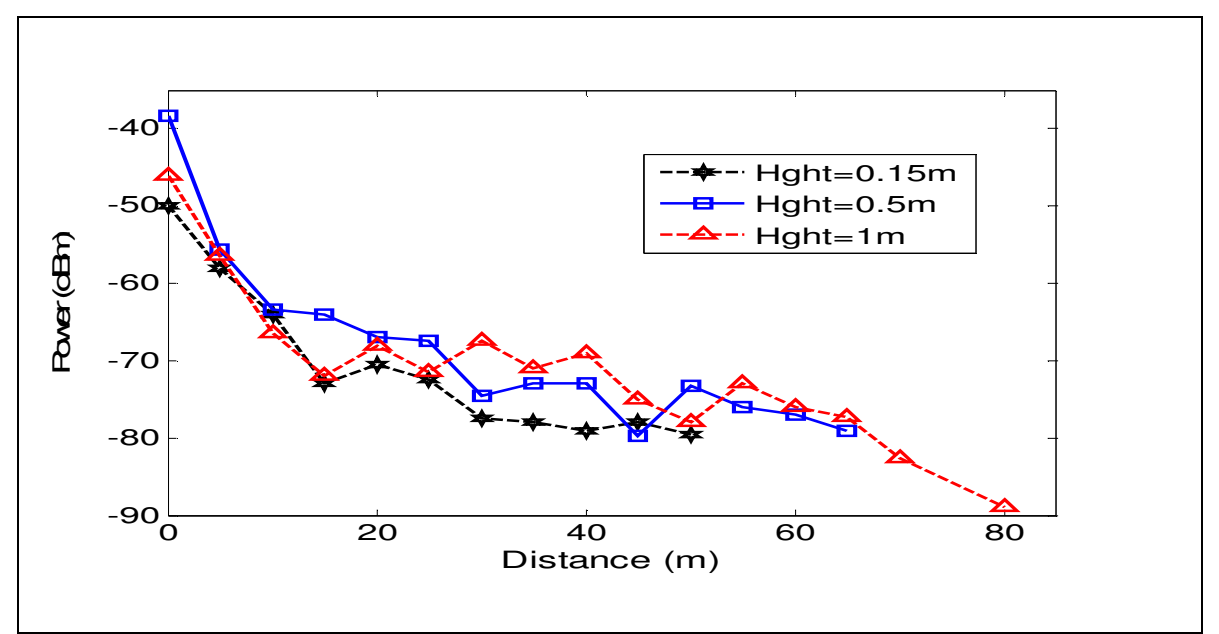

Fig. 7 Received signal variation with distance for $0.15 \mathrm{~m}, 0.5 \mathrm{~m}$ and $1 \mathrm{~m}$ antenna heights

$$
\mathrm{h}_{0}=\frac{1}{2} \sqrt{\lambda \mathrm{d}}
$$

where $d$ is the antenna separation and $\lambda$ is the wavelength. For $2.4 \mathrm{GHz} h_{0}$ is $0.5 \mathrm{~m}$ at a distance of $8 \mathrm{~m}$ and $1.0 \mathrm{~m}$ at a distance of $32 \mathrm{~m}$. Contributions from ground reflected signal components therefore can significantly influence the received signal power. The first Fresnel zone blockage increases with antenna separation after this point. Although the difference in the averaged received power is only $1 \mathrm{~dB}$ at $65 \mathrm{~m}$, the packet loss for $0.5 \mathrm{~m}$ antenna height 
increased to $100 \%$ beyond this point due to the poor quality of the received signal. This study shows that the range increases by $15 \mathrm{~m}$ when the antenna height is increased from $15 \mathrm{~cm}$ to $0.5 \mathrm{~m}$ and a further $15 \mathrm{~m}$ when the height is increased to $1 \mathrm{~m}$.

\section{WSN MODELLING AND PLANNING}

In mixed crop farming, sensor node deployment and density is determined by the number of environmental factors to be monitored and their spatial variations. The determining factors include: crops types, plant root zones/depths, soil type, yield cycle, water/nutrient requirements at different stages in the yield cycle, meteorological conditions and topography. In mono-crop farming node density is mainly influenced by soil type, crop type, spatial variation and topography of the farm land. Different crops have different tolerances to drought, temperature, humidity and nutrient deficiency. These different requirements imply that in addition to ensuring optimum spatial condition sampling with sensors in autonomous systems, temporal context-aware fertigation must be implemented. In this study the envisaged network objectives are to monitor air temperature, humidity, soil moisture, soil water potential, soil nutrients, fruit maturity and ripeness, and other environmental parameters.

The investigated antenna height of $1 \mathrm{~m}$ is low enough to allow sensors deployed underground, on the surface and on crop branches to be connected to the wireless module without compromising data integrity. In this study the field is divided based on the types of crops.

Significant research has been carried out into network deployment patterns to determine the optimal number of sensor nodes required to achieve optimal network coverage and connectivity. Distinctions are made between node coverage, which is for information collection, and node connectivity which, is for information transmission. Fig. 8 illustrates some of the simple geometries often used in the simulation of node deployment and the number of connections between the nodes.

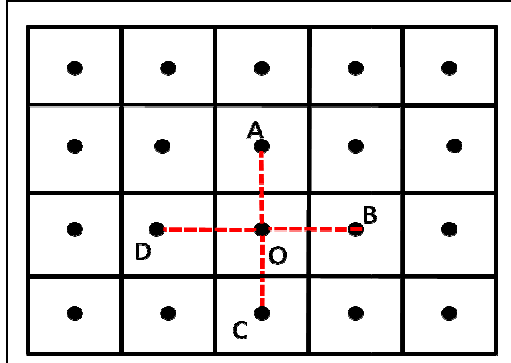

(a)

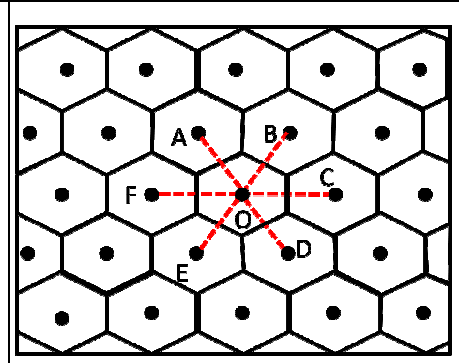

(b)

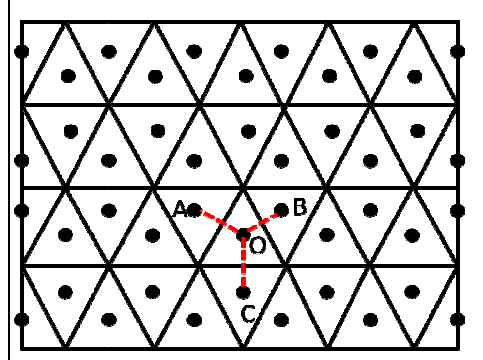

(c)

Fig. 8 WSN node deployment geometries and connectivity (a) square grid, (b) sexagone, and (c) triangle

Network coverage enables communication between nodes whilst connectivity provides fault tolerance. Connectivity can only exist if two nodes are within each other's communication range and a network with a high number of connectivity is resilient to fault but this must be balanced against costs. In order to model network coverage and connectivity, the following notations will be used:

- $\quad r_{c}$ denotes the communication range of a node;

- $\quad r_{s}$ is the spatial sampling resolution required;

- $A_{s}$ is the area covered by a node;

- $\quad \mathrm{N}$ is the number of nodes in the network ;

- $\quad C_{i}$ is the $\mathrm{i}^{\text {th }}$ network cluster head

\subsection{Coverage and Connectivity Modelling}

Because of different plant root zones, spatial sampling and node deployment is determined by the different crops and their location within the farm. In order to plan the network adequately, the following criteria were used:

- $\quad$ For each plot, $P_{i}$, a minimum of 2 sensor nodes will be used; 
- If there are only 2 nodes within a crops plot, $r_{s}<\frac{\sqrt{\left(X^{2}+Y^{2}\right)}}{2}$, where $X$ and $Y$ are the dimensions of a rectangular plot. In this case, $r_{c} \geq r_{s}$;

- A maximum node range $R_{\max }$ is used irrespective of the vegetation type to mitigate network partitioning due to time variant vegetation density.

For most network modeling, environmental homogeneity or random generated heterogeneous model parameters are often used to compute the path loss. This results in nodes having the same or unrealistic ranges. For these systems, deployment can be easily modeled and connectivity pattern accurately controlled. For mixed crops the node coverage range is not uniform. The range has to be calculated across crop plot boundaries. In Fig. 9, using equation (4), assume that for plots 1 and 2 signal propagation are characterized by $\left\{P_{01}, n_{1}\right\}$ and $\left\{P_{02}, n_{2}\right\}$ where $P_{0}$ and $n$ are the values given in Table 2 for different crop types.

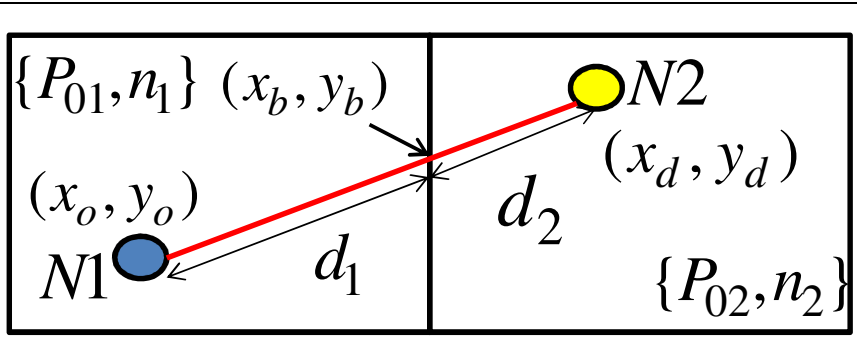

Fig. 9 Cross-crop plot node coverage

The path length between nodes $N 1$ and $N 2$ is $R=\sqrt{\left(x_{d}-x_{o}\right)^{2}+\left(y_{d}-y_{o}\right)^{2}}=d_{1}+d_{2}$. If a receiver node sensitivity is $P_{r m i n}$ the maximum range of $N 1$ is given by

$$
R_{N 1}=\sqrt{\left(x_{b}-x_{o}\right)^{2}+\left(y_{b}-y_{o}\right)^{2}}+10^{\left(\frac{\mathrm{P}_{\mathrm{rmin}}-\mathrm{P}_{\mathrm{r} 1}+\mathrm{P}_{01}}{-10 \mathrm{n}_{2}}\right)}
$$

Where $P_{r 1}$ is the signal strength at $\left(x_{b}, y_{b}\right)$. For this to be valid, $P_{r 1} \geq P_{r m i n}$ condition must be $\operatorname{satisfied}$ at $\left(x_{b}, y_{b}\right)$. The use of this environment aware model allows the link margin and also power level of each node to be individually modeled. Adaptive power control can be built into the system, especially as crop growth pattern varies amongst species and over short-to-long time period.

For the mixed crop area, using a uniform coverage model produces a network connectivity as illustrated in Fig. 10a. All the nodes achieve the 2-connectivity required for basic network fault tolerance but the network performance is overestimated. Setting a larger value for uniform node range will also produce over optimistic results. Fig. 10b shows the network connectivity when the network is adapted to the type of vegetation, using results in Table 2 . The network connectivity adapts to the prevailing environment and the node deployment can be optimized to meet specific spatial sampling and connectivity requirements.

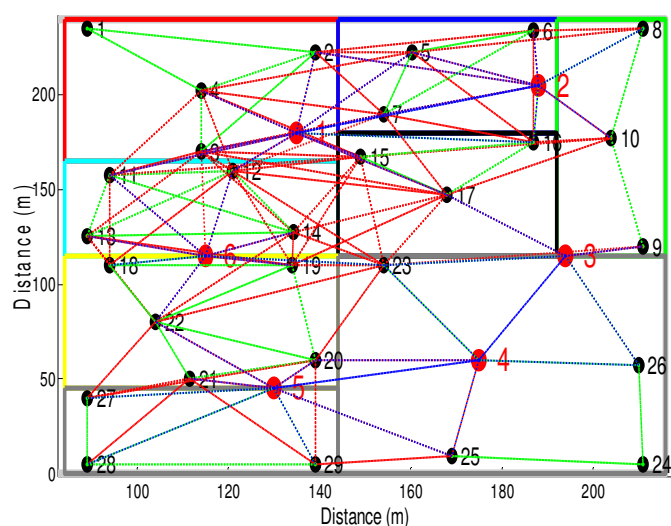

(a)

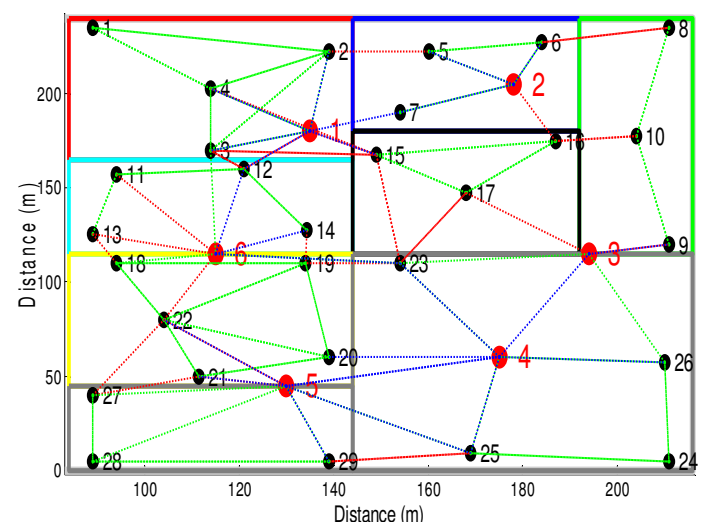

(b)

Fig. 10Wireless sensor node coverage and connectivity (a) uniform node coverage range, and (b)using vegetation specific network coverage 
Network deployment shown in Fig. 10 has a high nodes density and may have a high redundancy. Nonetheless some applications of WSN, especially in intensive agriculture such as in aquaculture, may demand such a high node density. The costs of the network include the initial cost of the motes and the running cost.

Most simulation studies use the two-ray model which often incorporates the direct ray and the reflected ray. At sufficiently long distances, the model simplifies to the Plane Earth model for which doubling the antenna height is equivalent to increasing the transmit power by $6 \mathrm{dBm}$. This model, when it has been used in network simulation studies, assumes surface homogeneity which will not be valid in most agricultural environments.

\subsection{Reciprocal Connectivity}

In wireless network modeling, channel symmetry is often widely assumed. In some networks were adaptive power control is used; a receiving node (D) collects information about the signal level and quality (signal-tonoise/interference level) from transmitting node (T). Then it uses this information to select the transmit power level that it needs to communicate with the original sender $(\mathrm{T})$. This makes two fundamental assumptions about the wireless channel:

- The receiving node is experiencing the same interference level as the transmitting node;

- The channel is homogeneous between the transmitter and the receiver.

This can lead to an excessive transmit power settings if the receiving node experiences interference from nodes that may be close to it but not to the destination node.

In signal propagation, especially in the presence of vegetation, there are three regions (depending on the vegetation depth) that are dominated by different propagation characteristics: coherent, forward scatter and diffused regions. This forms the basis of the Radiative Energy transport theory that has been applied to vegetation in [29] and represented by a 3 gradient model in [30]. Fig. 3 to Fig. 5 show that the rate of signal decay in the first 5 to 10 meters is much higher than subsequently, with the gradient depending on the type and, hence, density of the vegetation. This is followed by the forward scatter region which contains a mixture of coherent and scattered components and the gradient is smaller than in the coherent region. The multiple components in the diffused region combine to represent a small decay gradient with distance. However, communication in this region is characterized by multiple retransmissions due to high packet error ratio which reduces the battery lifetime of the node. Nodes that are located in high vegetation density plots, such as in the corn fields, may be able to receive transmissions from nodes located in other plots but may be unable to relay their own data because of the high extinction rate of the coherent signal in the first few meters from the node. This creates an asymmetry in communication between the two nodes that are located in two different plots with different crop types or densities. Mandke et al [31] have argued that ambient interference, hardware impairments and fading properties of wireless channels must be fully evaluated due to the potential cross-layer consequences for communications between two entities on an asymmetric link. This asymmetry in communication can be built into the network simulation model.

\subsection{Network Energy Consumption Modeling}

Base on the network connectivity, the power consumed in the network can be computed. WSN nodes have three energy consumptions states: sleep, transmit and receive. Using the energy model presented in [32], the energy consumption during transmission, when receiving and in the sleep state can be represented by

$$
\begin{aligned}
& E_{T x}=P_{T x} \times t_{T x} \\
& E_{R x}=P_{R x} \times t_{R x} \\
& E_{\text {sleep }}=P_{\text {slp }} \times t_{\text {slp }}
\end{aligned}
$$

where $P_{T x}, P_{R x}$ and $P_{s l p}$ are the power settings used when transmitting, receiving and in the sleep state. The parameters $t_{T x}, t_{R x}$ and $t_{s l p}$ are the time duration when the mote is transmitting, receiving and sleeping, respectively. The time duration depends on the amount of data to transmit and the data transmission rate. The time period when the motes are in the transmission and reception states increases with increase in interference level, path loss and packet collision, although the amount of data to be transmitted is the same using automatics retransmission.

Table 3 WSN Simulation Parameter based on Atmel ZigBee Chip Specification [32]

\begin{tabular}{|l|l|}
\hline Parameter & Value \\
\hline
\end{tabular}




\begin{tabular}{|l|l|}
\hline Number of nodes per plot & $1 \leq$ number of nodes $\leq$ diagonal distance/node range in plot \\
\hline Data packet size & 100 bytes \\
\hline Transmission interval & 15 minutes \\
\hline Required battery voltage & $1.8 \mathrm{~V}$ \\
\hline Transmit power levels & $-10 \mathrm{dBm}$ to $3 \mathrm{dBm}($ steps of $1 \mathrm{dBm})$ \\
\hline Receiver sensitivity level & $-91 \mathrm{dBm}$ \\
\hline Data rate & $250 \mathrm{~Kb} / \mathrm{s}$ \\
\hline $\mathrm{E}_{\mathrm{Rx}}$ & $0.113 \mathrm{~mJ}\left(\mathrm{I}_{\mathrm{Rx}}=19.7 \mathrm{~mA}\right)$ \\
\hline $\mathrm{E}_{\mathrm{Sleep}}$ & $144 \mathrm{~nJ}\left(\mathrm{I}_{\text {Sleep }}=80 \mathrm{nA}\right)$ \\
\hline
\end{tabular}

The transmit power of each node is adjusted based on its distance from neighbouring nodes, its connectivity and the signal to noise ratio computed using node receiver sensitivity level of $-91 \mathrm{dBm}$. The flow diagram of the simulation is shown in Fig. 11. The initial battery voltage is $3.0 \mathrm{~V}$.

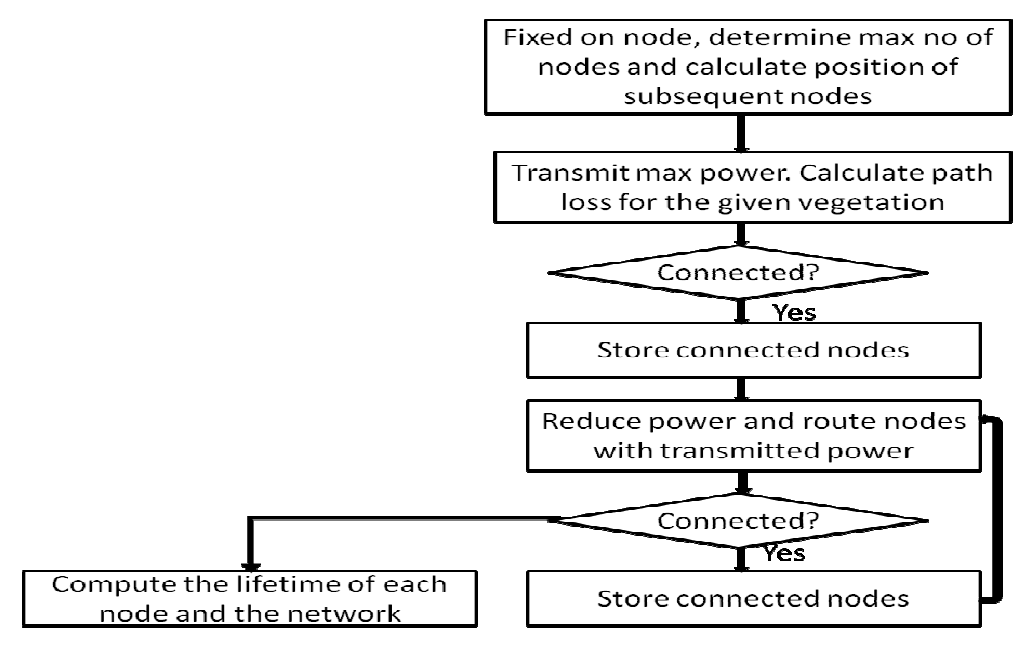

Fig. 11Flow diagram of network simulation to compute node placement and network life time

In an ideal system, all nodes must achieve a minimum of 2-connectivity for fault tolerance. However, this can be achieved at the expense of cost. Self-organizing and ad-hoc properties of the network allow nodes to join and leave the network with little or no disruption to normal operations. Therefore, the simulation initially aims for a minimum number of nodes to be deployed. The interest is in node connectivity and complete network connectivity. Fig. 12 shows the minimum node deployment that provides one redundancy (back-up) for each plot, except in plots P1 and P7 where there are more than two nodes. Fig. 12a(i) shows a possible placement of nodes that achieve a 59\% 2connectivity. Fig. 12a(ii) shows that the number of nodes with 2-connectivity can be achieved at the expense of network segmentation. An optimum network is one whose connectivity remains fairly stable over a wide range of signal level conditions. As shown in Fig. 12b(i), only one node losses 2-connectivity over a $7 \mathrm{~dB}$ received signal range. This reduces the possibility of network segmentation and provides flexibility for the implementation of transmission power control. Spatial sensing coverage and network connectivity are opposing requirements that must be optimized to eliminate network segmentation whilst providing fault tolerance. Fig. 13 presents an alternative to Fig. 12a(i). Although three nodes lose 2-connectivity over an $8 \mathrm{~dB}$ range, it offers better connectivity than Fig. 12a(i). 


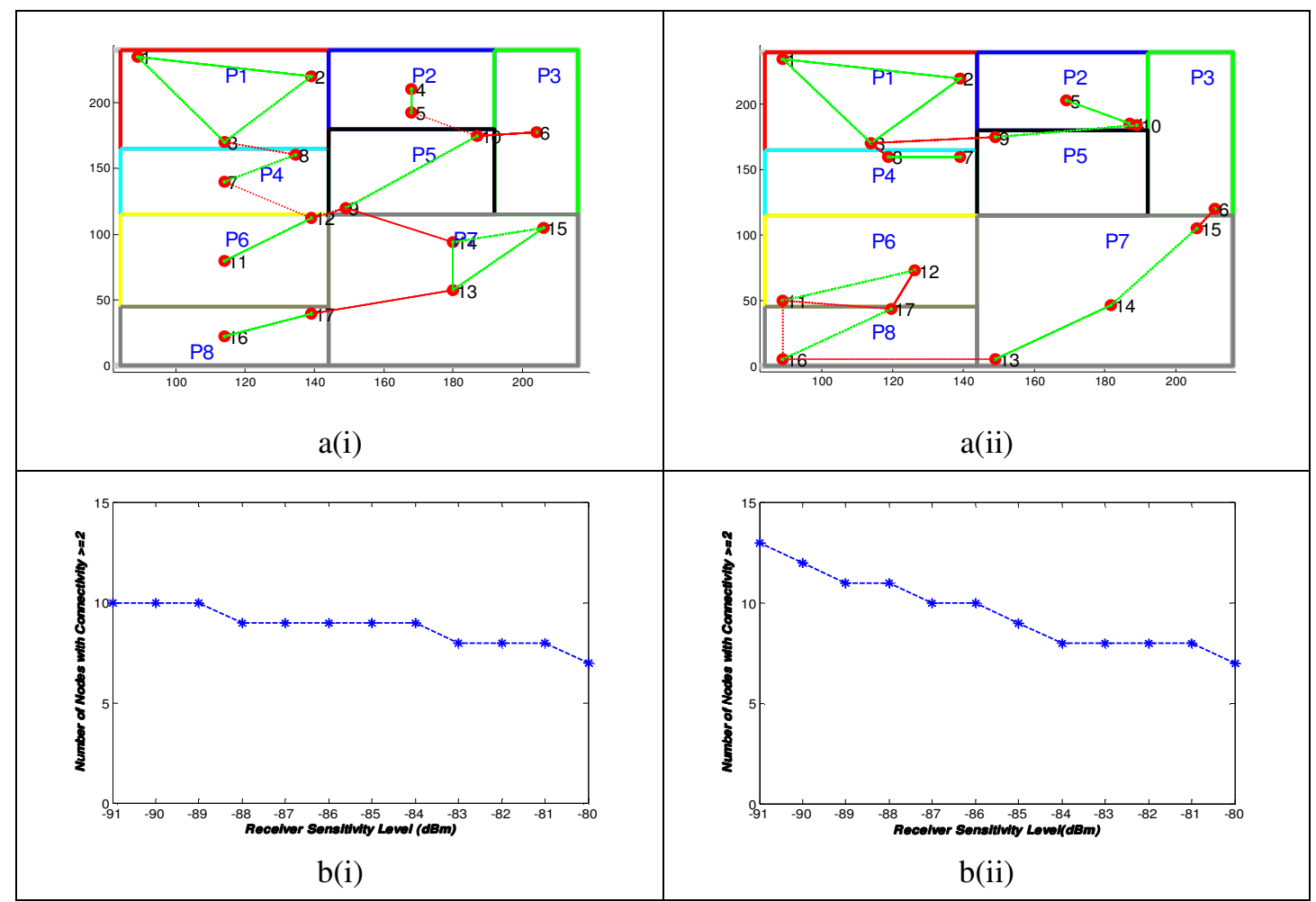

Fig. 12 Simulated network, (a) node placement and, (b) number of nodes with 2 or more connectivity

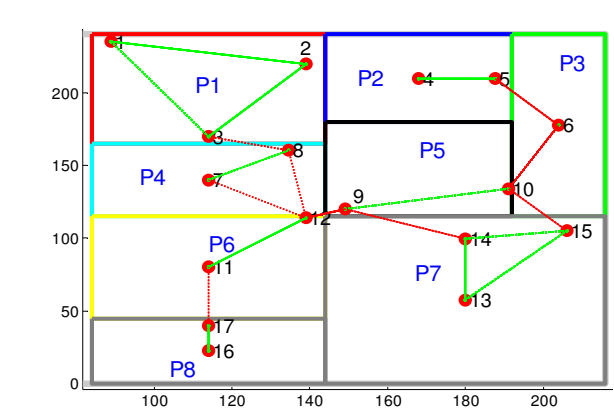

(a)

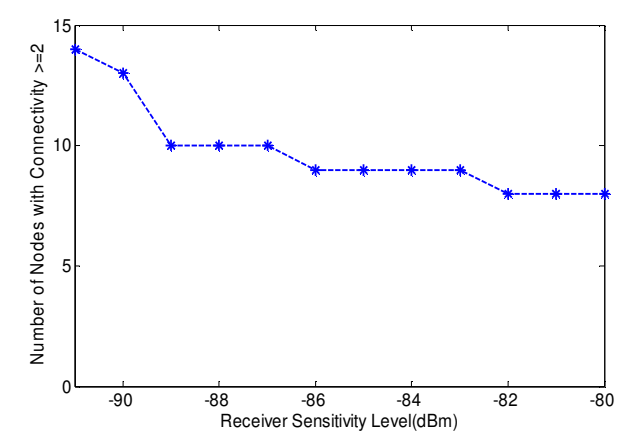

(b)

Fig. 13 Simulated network (a) node positions and, (b) number of nodes with 2 or more connectivity

Fig. 14 shows a network with node 12 acting as a sink node. The base station (node 12) is assumed to have unlimited power reserve. Fig. 14b can be used to select the transmit power levels of the nodes. From the node deployment diagram, only node 1 is shown to have only one connection but Fig. 14b shows that there are 4 nodes with only a single connectivity. This discrepancy is due to non-reciprocity or asymmetry of the channel between particular node pairs. Networks operating in this environment must be configured to broadcast without handshaking to circumvent problems associated with asymmetric channels. 


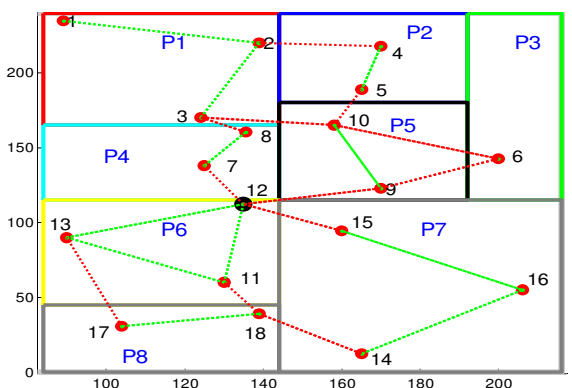

(a)

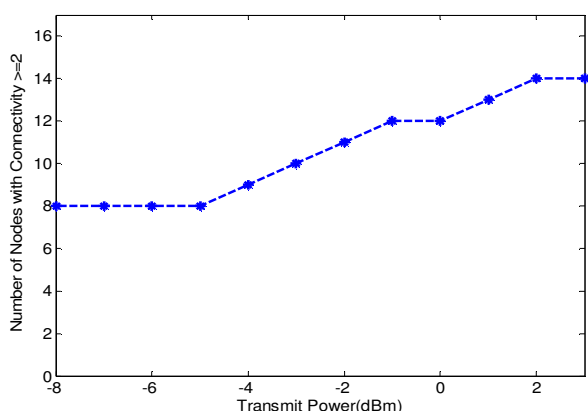

(b)

Fig. 14One network deployment optimised solution (a) node position and, (b) number of nodes with 2 or more connections

Using minimum power routing for data transmission in the network in Fig. 14, the energy consumption profile of the network and the number of nodes alive is shown in Fig. 15. The use of minimum nodes deployment strategy means that when the number of nodes alive drops to 6 , the network is segmented. This problem can be alleviated by using multi-height deployment with coordinating nodes that are deployed above vegetation height to act as cluster heads. This allows a uniform deployment topology to be used for cluster head network. In this case the network is decomposed into heterogeneous and homogeneous topology.

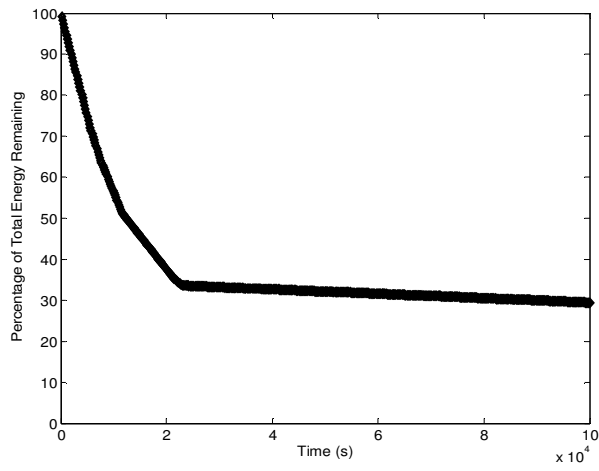

(a)

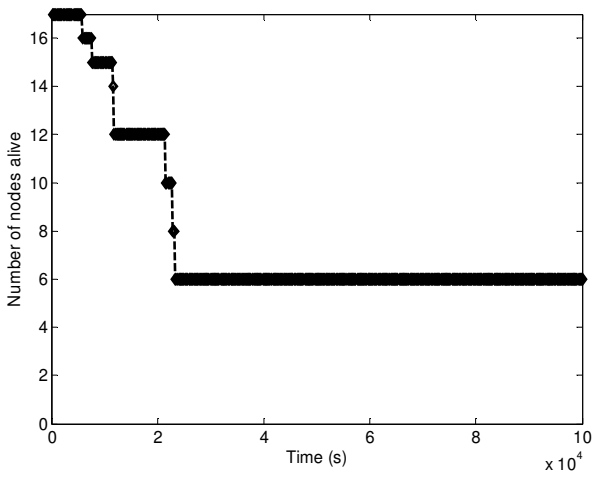

(b)

Fig. 15 (a) Percentage of total energy remaining in the network and, (b) the number of nodes alive in the network.

Applying this scheme, the network can be planned in 3-dimension allowing connectivity between nodes, nodes to cluster head and connections between cluster heads. This approach has two main advantages; it allows for the number of nodes to be reduced and can also allow for greater spatial sampling. This is possible when the nodes that act as cluster heads have line of sight between connecting cluster heads. Optimization of spatial coverage and network lifetime could be achieved using one-hop configuration. If the cluster heads are assumed to have unlimited battery power (e.g. using solar power source), greater efficiency can be achieved with cluster heads providing the network backbone.

Given a cluster head height, $h_{C H}$, vegetation height $h_{V G}$, a node at position $(x, y)$ set at a height of $h_{N H}$, and cluster head positions $\left(x_{C H}, y_{C H}\right), n$ and $P_{0}$ from equation (3) for the vegetation type where the node is located, the path loss for transmission from a node to a cluster head is given by equation (11). This is illustrated in Fig. 16.

$$
\begin{aligned}
\mathrm{PL}=10 \log ( & \left.\frac{\left(\mathrm{h}_{\mathrm{VG}}-\mathrm{h}_{\mathrm{NH}}\right) \sqrt{\left(\mathrm{x}-\mathrm{x}_{\mathrm{CH}}\right)^{2}+\left(\mathrm{y}-\mathrm{y}_{\mathrm{CH}}\right)^{2}}}{\left(\mathrm{~h}_{\mathrm{CH}}-\mathrm{h}_{\mathrm{VG}}\right)}\right)-\mathrm{P}_{0} \\
& +\mathrm{FSL}\left(\sqrt{\left(\mathrm{x}-\mathrm{x}_{\mathrm{CH}}\right)^{2}+\left(\mathrm{y}-\mathrm{y}_{\mathrm{CH}}\right)^{2}}\left[1-\frac{\left(\mathrm{h}_{\mathrm{VG}}-\mathrm{h}_{\mathrm{NH}}\right)}{\left(\mathrm{h}_{\mathrm{CH}}-\mathrm{h}_{\mathrm{VG}}\right)}\right]\right)-\mathrm{L}
\end{aligned}
$$


Where $F S L(t)$ is Free Space Loss over a distance, $t$. After propagation through the vegetation, the signal would have already experienced the initial steep attenuation associated with the coherent signal. Therefore, a factor $\mathrm{L}$ is added to the equation to account for reduced losses from the air/vegetation interface when the signal has already gone through the vegetation.

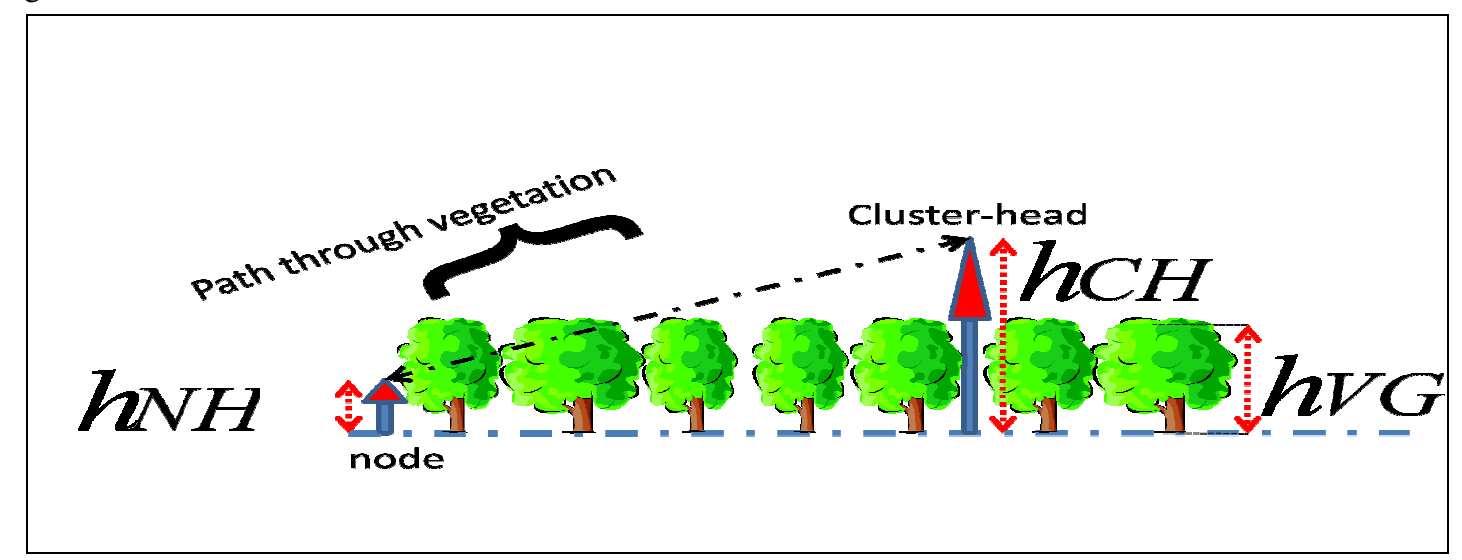

Fig. 16Illustration of cluster-head based heterogeneous height deployment system

An example of the network deployment using this scheme is shown in Fig. 17. Using the cluster-heads C1 to C5, with C5 acting as the data sink, all nodes in the network are within one hop from a cluster head. The connections between the nodes and cluster heads are shown in blue colour. The impact of the use of cluster heads is a reduction in the transmission power required by each node to transmit data to the sink. In this configuration, the stringent rule of a minimum of 2 connectivity can be relaxed, especially for nodes that connect directly to cluster heads.

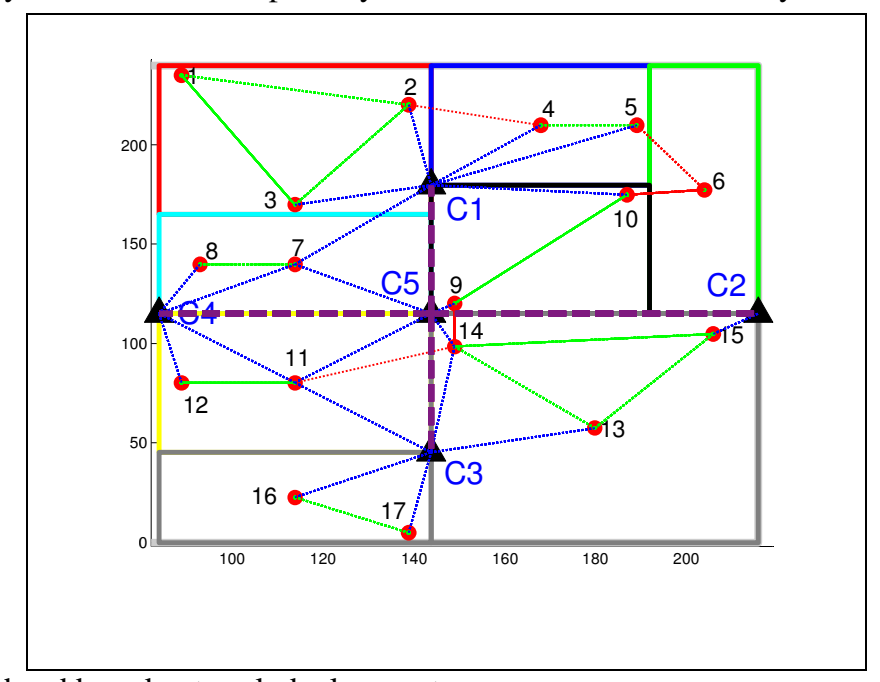

Fig. 17Cluster-head based network deployment.

Fig. 18 illustrates the energy consumption profile of the network and the number of nodes alive as a function of operation time. In computing the number of nodes alive, only the maximum available power path at the beginning of operation is used. However where a node has more than one path or connectivity, the node can change the next hop based on available power and therefore some nodes will operate for longer periods than shown in Fig. 18b. Using cluster heads, and considering only the energy of the sensor nodes, the total remaining energy in the network after $100,000 \mathrm{~s}$ of continual operations is $46.95 \%$ of the initial total energy compared to $29 \%$ in Fig. 15 . The network also operates for a time duration that is a factor 25 times longer compared to the network in Fig. 14 before the number of nodes alive in the network reduces to 6 . 


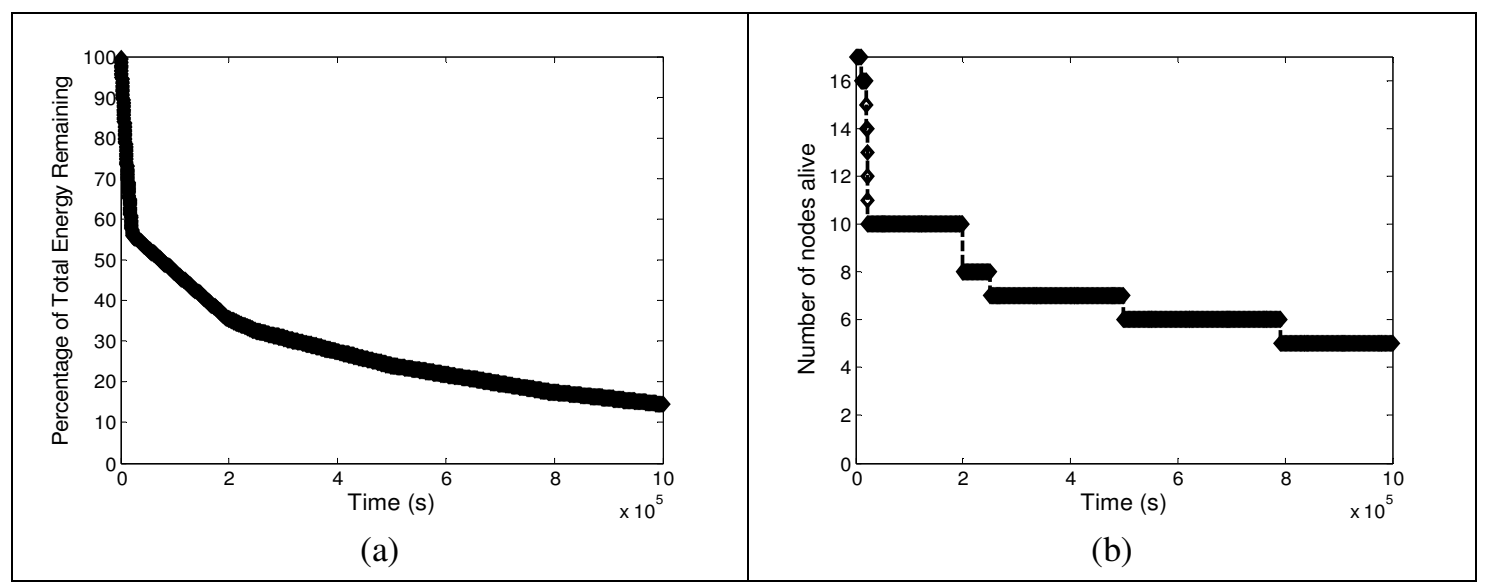

Fig. 18 (a) Percentage of total energy remaining in the network and, (b) the number of nodes alive in a cluster head based network.

\section{CONCLUSIONS}

Ad hoc wireless sensor network deployment in a heterogeneous environment presents unique challenges. For the purpose of network simulations and planning, the environment can be quantized into homogeneous units that can be described using channel propagation models for each specific channel. However communication between nodes in different areas characterized by different propagation medium must combine the different models to compute the link quality. In this paper, detailed measurements studies have been carried out in a mixed crop environment with different signal attenuation characteristics. Analysis showed that the best model to describe signal propagation in mixed crop environment is the log-distance model.

Two important factors have been considered in the planning of the network: the number of nodes and the nodeconnectivity. A minimum of 2 nodes were used in each crop plot to provide redundancy and in some instances more nodes can be deployed depending on the coverage required and the tolerance of the system/crops being monitored to changing conditions. Although a number of authors have proposed network deployment patterns, in heterogeneous environment network deployment pattern is dictated by the environment and uniform coverage pattern does not apply.

This study has shown that a two or more network height layers can lead to the conservation of network energy, potential reduction in the number of nodes to provide network coverage and an increase in network robustness as nodes do not have to rely on multiple hops to transmit data to the sink. This network structure can allow easy integration of different network standards e.g. Zigbee and WIFI with the cluster heads acting as gateways between the different standards.

\section{References}

[1] Riquelme, J. A. L., F. Soto, J. Suardiaz, P. Sanchez, A. Iborra and J.A. Vera, "Wireless Sensor Networks for precision horticulture in Southern Spain," Computers and Electronics in Agriculture, Vol. 68, 25-35, 2009.

[2] Nadimi, E.S., H.T. Sogaard, T. Bak and F. W. Oudshoorn, "ZigBee-based wireless sensor networks for monitoring animal presence and pasture time in a strip of new grass," Computers and Electronics in Agriculture, 1-9, 2007.

[3] Vougioukas, S., Anastassiu, H.T., Regen, C., Zude, M., "Influence of foliage on radio path losses (PLs) for wireless sensor network (WSN) planning in orchards", Biosystems Engineering (2012), http://dx.doi.org/10.1016/j.biosystemseng.2012.08.011

[4] Aqeel-ur-Rehman, Abbasi, A. Z., Islam, N., Shaikh, Z. A., A review of wireless sensors and networks' applications in agriculture, Comput. Stand. Interfaces (2011), doi:10.1016/j.csi.2011.03.004

[5] Yu, X.,Wu, P., Han, W., Zhang, Z., "A survey on wireless sensor network infrastructure for agriculture", Computers and Electronics in Agriculture, Vol. 35 (2013) 59-64. 
[6] Díaz, S. E., Perez, J. C., Mateos, A. C., Marinescu, M.-C., Guerra, B. G. "A novel methodology for the monitoring of the agricultural production process based on wireless sensor networks", Computers and Electronics in Agriculture 76 (2011) 252-265

[7] Huircána, J. I., Munoza, C., Younga, H., Dossowa, L.V., Bustosa, J., Vivallob, G., Toneattib, M., “ZigBeebased wireless sensor network localization for cattle monitoring in grazing fields", Computers and Electronics in Agriculture 74 (2010) 258-264

[8] Nadimi, E. S., H. T. Sogaard, T. Bak, "ZigBee-based wireless sensor networks for classifying the behaviour of a herd of animals using classification trees," Biosystems Engineering, 100 (2008), 167-176.

[9] Nadimi, E.S., H.T. Sogaard, T. Bak and F. W. Oudshoorn, "ZigBee-based wireless sensor networks for monitoring animal presence and pasture time in a strip of new grass," Computers and Electronics in Agriculture, 1-9, 2007.

[10] Mao, G., Anderson, B.D.O., Fidan, B., "Path loss exponent estimation for wireless sensor network localization" Computer Network, 51 (2007), pp. 2467-2483

[11] Somov, A., Baranov, A., Spirjakin, D., Spirjakin, A., Sleptsov, V., Passerone, R., "Deployment and evaluation of a wireless sensor network for methane leak detection", Sensors and Actuators: A Physical (2010), doi:10.1016/j.sna.2012.11.047

[12] Jabeen, F., Fernandes, A.A.A., "An algorithmic strategy for in-network distributed spatial analysis in wireless sensor networks”, J. Parallel Distrib. Comput. 72 (2012) 1628-1653

[13] Camilli, A., Cugnasca, C. E., Saraiva, A. M., Hirakawa, A.R., Corrêa, P.L.P., "From wireless sensors to field mapping: Anatomy of an application for precision agriculture", Computers and Electronics in Agriculture 58 (2007) 25-36

[14] Zerger, A., Rossel, R.A.V., Swain, D.L., Wark, T., Handcock, R.N., Doerr, V.A.J., Bishop-Hurley, G.J., Doerr, E.D., Gibbons, P.G., Lobsey, C., "Environmental sensor networks for vegetation, animal and soil sciences", International Journal of Applied Earth Observation and Geoinformation 12 (2010) 303-316

[15] Nadimi, E.S., Jørgensen, R.N., Blanes-Vidal, V., Christensen, S., "Monitoring and classifying animal behavior using ZigBee-based mobile ad hoc wireless sensor networks and artificial neural networks", Computers and Electronics in Agriculture 82 (2012) 44-54

[16] Ndzi D. L., Savage N., Gremont B., "Spatial and Temporal Variation of Wideband Indoor Channels", International Journal of Antennas and Propagation, vol. 2010, Article ID 735434, 11 pages, 2010.

[17] Petrova, M.; Riihijarvi, J.; Mahonen, P.; Labella, S.; "Performance study of IEEE 802.15.4 using measurements and simulations", Wireless Communications and Networking Conference, 2006. WCNC 2006, Las Vegas, USA. 3-6 April 2006, pages: 487 - 492

[18] Zhao, J., Govindan, R., "Understanding packet delivery performance in dense wireless sensor networks", Proceedings of First ACM Conference on Embedded Network Sensor Systems, New York, USA, 2003.

[19] Srinivasan, K., Levis, P., "RSSI is Under Appreciated",Proceedings of the Third Workshop on Embedded Networked Sensors (EmNets 2006)

[20] Zuniga, M., Krishnamachari, B., "Analyzing the transitional region in low power wireless links," IEEE Comms. Soc. Intl. Conf. on Sensor and Ad Hoc Communications and Networks (SECON), Santa Clara, USA, October 2004

[21] ATMEL AT86RF230 M, Low Power $2.4 \mathrm{GHz}$ Transceiver for ZigBee, IEEE 802.15.4, http://www.atmel.com/dyn/resources/prod_documents/doc5131.pdf, accessed 2 October 2011

[22] ITU-R Rec 833-6, Attenuation in vegetation, International Telecom. Union, Geneva, 2007, URL: http://www.itu.int/rec/R-REC-P.833-6-200702-I/en, accessed 23 October 2011.

[23] Ndzi, D. L., M. A. M. Arif, A. Y. M. Shakaff, M. N. Ahmad, A. Harun, L. M. Kamarudin, A. Zakaria, M. F. Ramli, and M. S. Razalli, "Signal Propagation Analysis for Low Data Rate Wireless Sensor Network Applications in Sport Grounds and on Roads", Progress In Electromagnetics Research, Vol. 125, 1-19, 2012.

[24] Savage N., Ndzi D.L., Seville A., Vilar E., Austin J., "Radiowave Propagation Through Vegetation: Factors Influencing Signal Attenuation”, Radio Science, 38(5), 1088, September-October 2003. 
[25] Meng, Y. S., Lee, Y. H., "Investigation of Foliage Effect on Modern Wireless Communication Systems: A Review”, Progress In Electromagnetics Research, Vol. 105, 313-332, 2010

[26] Ndzi D. L., L. M. Kamarudin, A. A. Muhammad Ezanuddin, A. Zakaria, R. B. Ahmad, M. F. b. A. Malek, A. Y. M. Shakaff, and M. N. Jafaar, "Vegetation attenuation measurements and modeling in plantations for wireless sensor network planning," Progress In Electromagnetics Research B, Vol. 36, 283-301, 2012.

[27] Al-Nuaimi, M.O., Stephens, R.B.L., "Measurements and prediction model optimization for signal attenuation in vegetation media at centimetre wave frequencies”, IEE Proc.-Micr. Ant. Prop., 145(3), 201-206, 1998.

[28] Weissberger, M.A., "An initial summary of models for predicting the attenuation of radio waves by trees", ESD-TR-81-101, EMC Analysis Center, Annapolis, MD, USA, 1982.

[29] Johnson, R. A., Shwering, F., "A Transport Theory of Millimeter Wave Propagation in Woods and Forests", CECOM Report, 1985

[30] QinetiQ, “A Generic Model of 1-60 GHz Radio Propagation Through Vegetation - Final Report”, Report Qinetiq/ki/com/cr0201961/1.0 2002. http://www.ofcom.org.uk/static/archive/ra/topics/research/topics/propagation/vegetation/vegetationfinalreportv1_0.pdf

[31] Mandke, K., Daniels, R.C., Choi, S-H., "Physical concerns for Cross-Layer Prototyping and Wireless Network Experimentation”, Proceedings of WiNTECH'07 Conference, Montreal, Canada, September 2007.

[32] Kamarudin, L.M., Ahmad, R.B., Ndzi, D., Zakaria, A., Ong, B.L., Harun, A., Kamarudin, K.Z., "Modeling and Simulation of WSNs for Agriculture Applications using Dynamic Transmit Power Control Algorithm,", ISMS 2012 - 3rd International Conference on Intelligent Systems, Modelling and Simulation, Kota Kinabalu, Malaysia, 8-10 February 2012

[33] Harun, A., Ndzi, D., Ramli, M., Shakaff, A., Ahmad, M. and Yanyan, Y. (2012) "Signal propagation in aquaculture environment for wireless sensor network applications", Progress in Electromagnetics Research, 131. pp. 477-494. ISSN 1070-4698 10.2528/PIER12072506 